\title{
Planejamento de informações públicas municipais: sistemas de informação e de conhecimento, informática e governo eletrônico integrados aos planejamentos das prefeituras e municípios*
}

Denis Alcides Rezende**

SuMÁrio: 1. Introdução e metodologia de pesquisa; 2. Planejamento de informação, conhecimento e informática nas prefeituras e municípios; 3. Planejamento estratégico municipal; 4. Metodologia de planejamento de informação, conhecimento e informática nas prefeituras e municípios; 5. Conclusão.

SUMMARY: 1. Introduction and research methodology; 2. Information, knowledge and IT planning in municipal governments and municipalities; 3. Municipal strategic planning; 4. Information, knowledge and IT planning methodology in municipal governments and municipalities; 5. Conclusion.

Palavras-chave: planejamento de informações; sistemas de informação; tecnologia da informação; governo eletrônico; planejamentos municipais; gestão de prefeituras e municípios.

KEY WORDS: information planning; information systems; information technology; electronic government; municipal planning; management of municipal governments and municipalities.

Os constantes desafios sociais, financeiros e políticos nos municípios têm exigido dos seus gestores uma atuação mais competente para propiciar qualidade de vida adequada aos seus munícipes. Com a participação da comunidade, os planejamentos municipais e as informações sistematizadas podem facilitar a gestão das prefeituras e dos municípios. Este artigo

\footnotetext{
* Artigo recebido em set. 2005 e aceito em nov. 2006.

** Professor-doutor pesquisador do Programa de Mestrado em Gestão Urbana da PUC-PR. Endereço: Rua Imaculada Conceição, 1155, Parque Tecnológico, Bloco 3 - Prado Velho CEP 80215-901, Curitiba, PR, Brasil. E-mail: denis.rezende@pucpr.br.
} 
descreve as fases, subfases e produtos de uma metodologia para planejamento de informação, conhecimento e informática nas prefeituras e municípios. A metodologia propõe nove fases, leva em conta os preceitos do empreendedorismo e pressupõe a necessidade da integração com os planejamentos municipais. A metodologia de pesquisa constitui uma abordagem de natureza aplicada numa realidade circunstancial, com ênfase no método indutivo favorecido pelas experiências vivenciadas do autor pesquisador. As contribuições estão direcionadas às prefeituras, aos municípios e aos munícipes que por meio de informações podem cooperar nos fatores competitivos entre as cidades, na forma de gestão da prefeitura e no aumento da qualidade de vida dos cidadãos. A conclusão reitera a importância da participação dos munícipes na gestão municipal e na condução cotidiana dos municípios.

Planning municipal public information: information and knowledge systems, IT and electronic government integrated to city government and municipal planning

The constant social, financial, and political challenges in municipalities have required from their managers a more competent action in order to offer an adequate life standard to their citizens. With the participation of the community, municipal planning and systematized information can help the management of city governments and municipalities. This article describes the phases, sub-phases and products of a method for information, knowledge and IT planning in city governments and municipalities. The method proposes nine phases, considers the precepts of entrepreneurship, and presupposes the need for integration with municipal planning. The research methodology consists of an applied approach in a circumstantial reality, with emphasis on the inductive method helped by the author's experience. The contributions are directed to city governments, municipalities and their population, in which information can help foster city competitiveness and improve city management as well as the life standards of the population. The conclusion reiterates the importance of citizen participation in city government as well as in the daily management of their cities.

\section{Introdução e metodologia de pesquisa}

Os constantes desafios sociais, financeiros e políticos nos municípios têm exigido dos seus gestores uma atuação mais competente para propiciar qualidade de vida adequada aos seus munícipes. Por outro lado, a participação dos munícipes na condução do município é uma necessidade inexorável. Uma das formas para contribuir nesses desafios é o planejamento estratégico trabalha- 
do de forma coletiva, onde as informações sistematizadas são pré-requisitos para as atividades de organização das prefeituras e dos municípios.

O planejamento estratégico municipal e o planejamento estratégico das informações municipais são instrumentos de gestão das prefeituras e dos municípios de relevância inquestionável. Principalmente pelas dificuldades dos recursos financeiros nos municípios, pela obediência à Lei de Responsabilidade Fiscal, pela exigência do Estatuto da Cidade e pelas pressões dos munícipes e dos interessados na cidade (atores sociais ou stakeholders). Essas pressões podem ser minimizadas pela elaboração e implementação desses planejamentos estratégicos participativos nos municípios, pois pode propiciar o envolvimento coletivo dos munícipes com seus anseios e também pode descentralizar e compartilhar as decisões dos gestores locais.

Este artigo descreve fases, subfases e produtos de uma metodologia para projeto de planejamento de informação, conhecimento e informática nas prefeituras e municípios. Visa também detalhar de forma objetiva a visão moderna e a aplicação adequada de um guia para planejamento das informações e dos conhecimentos das prefeituras e dos municípios. A metodologia proposta especifica nove fases, levando em conta os preceitos do empreendedorismo a serem aplicados no município e pressupondo a necessidade da integração desse projeto com o planejamento estratégico municipal. Também são contextualizados os demais planejamentos do município e suas formas de integração por meio das políticas municipais entre o planejamento plurianual, o plano diretor, os projetos participativos e o planejamento de recursos humanos. A metodologia de pesquisa empregada constitui uma abordagem de natureza aplicada numa realidade circunstancial, com ênfase no método indutivo favorecido pelas experiências vivenciadas do autor pesquisador, tanto em projetos de assessoramento em prefeituras quanto em projetos acadêmicos em sala de aula de graduação e mestrado. Contempla parcialmente conceitos da pesquisa exploratória no que tange ao levantamento bibliográfico e documental (Nachmias e Nachmias, 1987; Marconi e Lakatos, 1996; Gil, 1999).

\section{Planejamento de informação, conhecimento e informática nas prefeituras e municípios}

O planejamento de informação, conhecimento e informática nas prefeituras e municípios também pode ser chamado de planejamento estratégico da tecnologia da informação (Peti). Esse planejamento deve ser integrado e alinhado com os demais planejamentos municipais (planejamento estratégico, planejamento plurianual e plano diretor). 


\section{Informação nas prefeituras e municípios}

A informação é um recurso efetivo e inexorável para as prefeituras e municípios, principalmente quando planejada e disponibilizada de forma personalizada, com qualidade inquestionável e preferencialmente antecipada para facilitar as decisões dos gestores locais e também dos munícipes. O planejamento e a modelagem da informação também é um pré-requisito para a aquisição ou desenvolvimento de sistemas de informação, de softwares de governo eletrônico e de portais públicos municipais.

A informação pode ser entendida como um dado com valor significativo atribuído ou agregado a ele e com um sentido natural e lógico para quem usa a informação. Pode ser definida como algo útil. Como exemplos, podem ser citados: nome do munícipe; cor do automóvel; número de equipamentos; data de nascimento; valor do saldo bancário. Observa-se que sempre uma informação requer mais de uma palavra. Quando a informação é "trabalhada" por pessoas e pelos recursos computacionais, possibilitando a geração de cenários, simulações e oportunidades, pode ser chamada de conhecimento. O conceito de conhecimento complementa o de informação com valor relevante e propósito definido. Pode ser definido como percepções humanas (tácitas) ou inferências computacionais. Como exemplos, podem ser citados: percepção da dificuldade de reversão de prejuízo futuro de uma atividade da prefeitura; práticas que podem ser utilizadas em virtude do cenário atual, com base em experiências semelhantes anteriores; concepção de quais equipamentos, materiais e pessoas são vitais para um serviço; entendimentos de quais contratos ativos podem ser negociados, visando a adequação à realidade de uma atividade.

Toda e qualquer informação peculiar ou específica pode ser chamada de informação personalizada. Seja da "persona" física ou jurídica, de um serviço municipal, de um produto ou de um negócio diferenciado. Também pode estar relacionada com uma característica ímpar de um munícipe, prospect, cliente, consumidor ou concorrente e até mesmo de um produto ou serviço (Rezende, 2005a). Como exemplos desse tipo de informação podem-se citar: nome do lazer preferido de um munícipe; cor preferida de um cliente; marca de um produto predileto de um consumidor; peso de um hóspede de hotel; nome de uma doença peculiar de um paciente; data escolhida para visita de um vendedor; nome do banco eleito pelo pagador; nome de um serviço escolhido por um cidadão.

Toda e qualquer informação de qualidade inquestionável, porém antecipada, pode ser chamada de informação oportuna. A informação oportuna é a antítese da informação do passado e a que não gera um cenário futuro e indiscutível (Rezende, 2005a). Como exemplos desse tipo de informação podem-se citar: número de vagas no ensino fundamental no ano seguinte; quantidade de 
matéria-prima faltante no dia seguinte; número de unidades habitacionais disponíveis do hotel na semana seguinte; valor do saldo negativo bancário amanhã; número de peças produzidas na próxima hora; data do feriado do mês vindouro. Os dias, horas e demais números devem sempre ser definidos.

\section{Sistemas de informação}

Todo sistema, usando ou não os recursos da tecnologia da informação, que manipula e gera informação, pode ser genericamente considerado sistema de informação. Independentemente de seu tipo, nível ou classificação, os sistemas de informação têm como maior objetivo o auxílio nos processos de tomada de decisões organizacionais. Para os planejamentos municipais, o foco dos sistemas de informação está direcionado aos serviços municipais, principalmente ao atendimento ao cidadão, ao município e aos demais interessados na cidade (atores sociais ou stakeholders). Este foco está intimamente relacionado com os requisitos de qualidade, de produtividade, de efetividade e de inteligência organizacional da prefeitura e do município.

São incontestáveis os benefícios que os sistemas de informação oferecem, principalmente quando são utilizados como fatores de solução de problemas e como ferramentas de diferenciais (O’Brien, 2001).

Do ponto de vista do ciclo evolutivo, os sistemas de informação podem ser classificados em: manuais, mecanizados, informatizados, automatizados, e sistemas de informação gerenciais e estratégicos. Os sistemas de informação podem ser classificados quanto à abrangência na prefeitura, ou seja, nos níveis: pessoal, de grupo ou departamental, organizacional e interorganizacionais (Kroenke, 1992). A partir do planejamento das necessidades de informação na prefeitura ou município, os sistemas de informação podem ser classificados em: manutenção ou adaptação, desenvolvimento e aquisição. Outra classificação possível está relacionada com a forma de apoio ou suporte a decisões: sistemas de informação operacionais, gerenciais e estratégicos (Laudon e Laudon, 1996; Stair, 1996; Rezende, 2005b).

Os sistemas de informação operacionais contemplam o processamento de operações e transações rotineiras cotidianas, incluindo seus respectivos procedimentos. Na prefeitura pode ser, por exemplo, o sistema de arrecadação, o sistema de saúde, o sistema de educação e outros. Manipulam informações no seu detalhe, analítica ou singular. Por exemplo: nome do serviço; nome do munícipe; data do evento.

Os sistemas de informação gerenciais contemplam o processamento de grupos de dados das operações e transações operacionais, transformando-os 
em informações agrupadas para gestão. Na prefeitura pode ser, por exemplo, os sistemas relacionados com as funções municipais (educação, transporte, segurança, saúde entre outros). Manipulam informações agrupadas, sintéticas, totais, percentuais, acumuladores ou plurais. Por exemplo: número total de serviços elaborados; quantidade de serviços pendentes; número de obras realizadas; percentual de satisfação do munícipe.

Os sistemas de informação estratégicos contemplam o processamento de grupos de dados das operações operacionais e transações gerenciais, transformando-os em informações estratégicas. Na prefeitura também podem ser, por exemplo, os sistemas relacionados com as funções municipais. Trabalham com os dados no nível macro, filtrados das operações das funções organizacionais das empresas privadas ou funções municipais das prefeituras, considerando ainda os meios ambientes internos ou externos. Visam auxiliar o processo de tomada de decisão da alta administração, tal como, prefeitos, secretários, presidentes, diretores, assessores etc. Manipulam informações agrupadas e relacionadas (comparadas) com o meio ambiente interno ou externo. Por exemplo: número total de serviços elaborados versus número total de serviços planejados; quantidade de serviços pendentes versus quantidade de munícipes atendidos.

Para desenvolver ou adquirir sistemas de informação e sistemas de conhecimentos são necessários os modelos de informações e os mapas de conhecimento (Rezende, 2005b). O modelo de informações municipais descreve todas as informações necessárias para gestão da prefeitura e município. O mapa de conhecimentos municipais descreve os conhecimentos das pessoas que podem ser compartilhados. Nesses mapas são descritos os conhecimentos das pessoas a partir de seus respectivos capital intelectual, competências, habilidades e percepções para disseminar as melhores práticas da prefeitura ou município por meio de cenários, alertas, combinações, resultados de análises com reflexão, síntese e contextos orientados para ações.

\section{Sistemas de conhecimento}

O conhecimento da prefeitura ou município, que também pode ser chamado de capital intelectual, competência, habilidade, é reconhecido como um ativo intangível de inestimável valor. O compartilhamento dos conhecimentos pelos gestores locais, servidores municipais, cidadãos e demais interessados no município tem sido um grande e constante desafio para os municípios, por várias razões. Além das razões semelhantes às organizações privadas, a troca de 
governantes a cada quatro anos prejudica o compartilhamento de experiências adequadas e conseqüentemente dos conhecimentos acumulados.

A aquisição do conhecimento é um processo interno de compreensão das informações recebidas, que ocorre de forma diferente em cada indivíduo devido à existência de modelos mentais individuais, que podem resultar em ações e decisões completamente diferentes como resultados. O conhecimento também pode ser visto como "uma capacidade de agir" e é contextual não podendo ser destacado do ambiente (Sveiby, 1998). Na visão oriental a divisão cartesiana entre sujeito e objeto é rebatida, neste caso a criação do conhecimento ocorre de dentro para fora nas prefeituras ou municípios com o intuito de redefinir problemas e soluções procurando afetar seu ambiente (Nonaka e Takeuchi, 1997).

Sem fazer distinção entre tácito e explícito ou estabelecer duas dimensões para o conhecimento, ele é reconhecido como uma mistura de elementos formalmente estruturados e intuitivos. No caso do conhecimento intuitivo, sua representação e seu entendimento lógico são mais difíceis (Davenport e Prusak, 1998). O conhecimento é uma derivação da informação manipulada a partir de dados. A geração do conhecimento ocorre quando as informações são comparadas, combinadas e analisadas por pessoas, principalmente quando utilizadas nos processos decisórios. A gestão do conhecimento pode ser entendida como uma forma de gestão ou administração, compartilhamento e aproveitamento do conhecimento das pessoas e disseminação das melhores práticas para o crescimento da prefeitura ou município (Santos et al., 2001; Rezende, 2002).

Todo e qualquer sistema que manipula ou gera conhecimentos organizados para contribuir com os seres humanos, com as prefeituras, com os municípios e com a sociedade como um todo, pode ser chamado de sistema de conhecimento (Rezende, 2005b). Os sistemas de conhecimento podem ser compostos pelos recursos emergentes da tecnologia da informação ou por simples softwares específicos, onde são geradas informações com conhecimentos agregados. O que significa a difusão das informações relevantes e úteis, "trabalhadas" por pessoas ou por recursos computacionais, produzidas com qualidade e de forma antecipada, transformando-as em conhecimento explícito, que possa ser utilizado por todas as pessoas da prefeitura ou município, como suporte à obtenção da vantagem competitiva inteligente (Davenport e Prusak, 1998; Laudon e Laudon, 1996; Rezende, 2002).

As pessoas e suas competências e habilidades podem fazer com que os sistemas de conhecimento funcionem de fato como componentes responsáveis pela excelência das prefeituras ou municípios bem-sucedidos e pelo aporte de capital intelectual que simboliza a importância do fator humano contextualizadas. Para que as prefeituras ou municípios obtenham as vantagens e utilidades 
efetivas desses sistemas, é exigido o emprego e a integração dos recursos da tecnologia da informação.

Os sistemas de informação operacionais, gerenciais e estratégicos manipulam e geram as respectivas informações oportunas a partir da base de dados única. Essas informações são respectivamente, no detalhe, agrupada e macro, que relaciona as mesmas com o meio ambiente interno ou externo da prefeitura ou município. Os sistemas de conhecimento manipulam e geram conhecimentos a partir das "bases de conhecimento". As bases de conhecimento são o local onde são depositados conhecimentos expressos em dados não-triviais, imagens, sons, raciocínios elaborados etc. O conhecimento é oriundo da "base de dados" e do meio ambiente interno e externo à prefeitura ou município. Ambas as bases (de dados e de conhecimentos) são criadas pelas pessoas da prefeitura ou município e acionadas por meio dos recursos da tecnologia da informação.

Os recursos e os componentes da tecnologia da informação são os responsáveis pelas atividades de geração, troca e integração (sinergia) dos dados, informações e conhecimentos. Esses recursos podem ser qualquer software desenvolvido em linguagens de programação convencionais ou também software específico para esse fim, tais como, recursos de inteligência artificial ou sistemas especialistas, sistemas gerenciadores de banco de dados, ferramentas baseadas na internet e portais, gerenciamento eletrônico de documentos, automação de processos; e outras ferramentas ou aplicativos.

Toda a sinergia desses sistemas é trabalhada pelos técnicos e gestores da prefeitura ou município com seus respectivos capitais intelectuais, competências, habilidades e conhecimentos tácitos e explícitos.

\section{Informática ou tecnologia da informação}

A informática ou tecnologia da informação (TI) pode ser conceituada como recursos tecnológicos e computacionais para guarda de dados, geração e uso da informação e do conhecimento (Stair, 1996; Rezende, 1999). Está fundamentada nos seguintes componentes: hardware e seus dispositivos e periféricos; software e seus recursos; sistemas de telecomunicações; gestão de dados e informações. Todos esses componentes interagem e necessitam do componente fundamental que é o recurso humano, peopleware ou humanware. Embora conceitualmente esse componente não faça parte da tecnologia da informação, sem ele a tecnologia não teria funcionalidade e utilidade.

O hardware contempla os computadores e seus respectivos dispositivos e periféricos. O software contempla os programas nos seus diversos tipos, tais 
como, o software de base ou operacionais, de redes, aplicativos, utilitários e de automação. Eles dirigem, organizam e controlam os recursos de hardware, fornecendo instruções, comandos, ou seja, programas.

Os sistemas de telecomunicações são recursos que interligam o hardware e o software. As comunicações podem ser definidas como as transmissões de sinais por um meio qualquer, de um emissor para um receptor. As telecomunicações se referem à transmissão eletrônica de sinais para comunicações, inclusive meios como telefone, rádio e televisão. As comunicações de dados são um subconjunto especializado de telecomunicações que se referem à coleta, processamento e distribuição eletrônica de dados, normalmente entre os dispositivos de hardware de computadores.

A gestão de dados e informações com seus respectivos recursos, parte integrante da tecnologia da informação, também são subsistemas especiais do sistema de informação global das organizações. Os dados, quando a eles são atribuídos valores, transformam-se em informações. A gestão de dados e informações compreende as atividades de guarda e recuperação de dados, níveis e controle de acesso das informações (Norton, 1996; Stair, 1996; Laudon e Laudon, 1996). Essa gestão contempla quatro atividades relevantes: esquema de guarda de dados (cópia ou backup), recuperação de dados, controle de acesso e níveis de acesso ou de navegação sistêmica. Requerendo para essa gestão um completo plano de contingência e um plano de segurança de dados e informações.

\section{Planejamento estratégico de informações ou da tecnologia da informação}

Uma vez descrita a relevância e os conceitos de sistemas de informação e de conhecimento e da informática ou tecnologia da informação é importante conceituar, justificar e reiterar a importância desse planejamento.

Apesar de tratar os recursos técnicos, o planejamento estratégico de informações ou da tecnologia da informação difere do antigo plano diretor de informática (PDI). O planejamento estratégico de informações ou da tecnologia da informação preocupa-se mais com as informações e com os conhecimentos de toda a prefeitura ou município. Já o PDI tem seus esforços mais direcionados para a tecnologia da informação e seus respectivos recursos tecnológicos focados na configuração do hardware, do software e das telecomunicações (Rezende, 2003). O planejamento estratégico de informações (PEI) ou planejamento estratégico da tecnologia da informação (Peti) unifica as diversas nomenclaturas e abreviações anteriores. Com relação ao 
conceito de Peti, ele é um conjunto de ferramentas e técnicas que possibilitam a definição de estratégias de ação ao longo de um período de aproximadamente um a três anos, visando: identificar os "modelos de informações municipais" e os "mapas de conhecimentos" necessários à gestão da prefeitura ou município, para tomada de decisões em todos os níveis (estratégicos, táticos e operacionais); estabelecer ferramentas de controle de qualidade, produtividade, efetividade, prazos e custos; elaborar plano de desenvolvimento (ou aquisição), implantação, implementação de sistemas de informação (estratégicos, de gestão e operacionais) e sistemas de conhecimentos; planejar recursos humanos; padronizar e simplificar a tecnologia da informação; planejar recursos da tecnologia da informação; identificar planos de ação imediatos e de curto prazo (Rezende, 2002).

O tempo de reavaliação dos planejamentos pode variar de prefeitura (ou município) para prefeitura (ou município) e de suas respectivas características, mas de maneira geral deve ser reavaliado de forma trimestral, semestral ou até mesmo anual. Deve-se também observar a reavaliação em condições situacionais ou especiais (Rezende e Abreu, 2003). O período da abrangência do planejamento estratégico da tecnologia da informação não pode ser muito longo, tendo em vista principalmente as mudanças tecnológicas e as diferentes características da prefeitura ou município em questão. As revisões desse planejamento, tal como do planejamento estratégico municipal, devem ocorrer num prazo médio entre três e seis meses, salvo situações emergenciais tecnológicas, de ameaças ou oportunidades.

Concluindo, o Peti é um roteiro ou guia dinâmico para planejamento estratégico, tático e operacional das informações e dos conhecimentos municipais. E como conseqüência, da tecnologia da informação e seus recursos (hardware, software, sistemas de telecomunicação e gestão de dados e informação), dos sistemas de informação, das pessoas envolvidas e a infra-estrutura necessária para o atendimento das decisões e ações municipais. Deve ser elaborado por uma equipe multidisciplinar por meio de fases e subfases interativas, as quais geram produtos para revisão e aprovação da qualidade, que contribuem com os tomadores de decisões nas prefeituras e municípios.

\section{Integração e alinhamento dos planejamentos}

O planejamento estratégico municipal (incluindo os demais planejamentos municipais, ou seja, o planejamento plurianual e o plano diretor) e o planejamento dos sistemas de informação e de conhecimentos e da informática ou 
tecnologia da informação devem estar integrados. Essa integração é determinada principalmente pelos respectivos objetivos e estratégias alinhadas e com sinergia entre si.

A integração dos planejamentos requer que o planejamento estratégico municipal esteja alinhado com suas funções por meio dos objetivos e das estratégias municipais. As funções municipais são: serviços municipais, marketing, materiais ou logística, financeira, recursos humanos e jurídico-legal. Os objetivos e as estratégias municipais subsidiam o planejamento estratégico da tecnologia da informação (Peti) que analisa e planeja os sistemas de informação, os sistemas de conhecimentos, as tecnologias da informação e os perfis profissionais necessários para a realização do planejamento estratégico municipal e os demais planejamentos municipais.

O Peti essencialmente planejará os sistemas de informação (operacionais, gerenciais e estratégicos) e os sistemas de conhecimento. A partir desses sistemas, organizará a necessidade da informática ou tecnologia da informação (TI) e seus recursos juntamente com a definição dos perfis das pessoas ou dos recursos humanos coerentes com as propostas da prefeitura e do município. Todas essas variáveis devem contemplar o princípio da sinergia, ou seja, coerência, integração e alinhamentos vertical e horizontal. Isso significa dizer que todos os sistemas que são planejados devem estar relacionados com os objetivos e as estratégias municipais apresentadas no planejamento estratégico (Rezende, 1999; Rezende, 2003).

O alinhamento do planejamento estratégico municipal ao planejamento estratégico da tecnologia da informação constitui-se pela dinâmica relação vertical e horizontal com os respectivos ambientes externos e internos à prefeitura e ao município. O alinhamento pode ser sustentado por quatro grandes grupos de fatores ou construtos: tecnologia da informação; sistemas de informação e sistemas de conhecimento; pessoas ou recursos humanos; e contexto ou infra-estrutura organizacional (Rezende, 2002). O alinhamento entre os planejamentos se centraliza em três dimensões: planejamento estratégico de tecnologia da informação, planejamento estratégico municipal e recursos sustentadores do alinhamento entre os planejamentos. As dimensões do modelo são desmembradas em construtos. O conjunto de construtos é dividido em cinco partes: tecnologia da informação; sistemas de informação e sistemas de conhecimentos; pessoas ou recursos humanos; contexto ou infra-estrutura organizacional e alinhamento estratégico entre os planejamentos. E cada construto é formado por suas variáveis. A adequação desses construtos propicia o referido alinhamento dos planejamentos. 


\section{Planejamento estratégico municipal}

O planejamento estratégico e os demais planejamentos municipais (planejamento plurianual e plano diretor) constituem ferramentas indispensáveis para a gestão das prefeituras e dos municípios. Principalmente pelas dificuldades dos recursos financeiros nas prefeituras e municípios, pela obediência à Lei de Responsabilidade Fiscal, pela exigência do Estatuto da Cidade e pela pressão dos munícipes, dos gestores locais e dos demais interessados na cidade (atores sociais ou stakeholders). A Constituição Federal e a Lei Orgânica Municipal também devem ser consideradas nesse projeto, onde os anseios dos cidadãos ou munícipes devem ser respeitados e participados.

\section{Planejamentos municipais}

Os planejamentos municipais envolvem múltiplas modalidades e requerem suas integrações para facilitar a gestão municipal e contribuir com a qualidade de vida dos munícipes. Podem ser compostos dos seguintes componentes: planejamento estratégico, planejamento plurianual e plano diretor.

O planejamento plurianual é exigido pela Constituição Federal de 1988 (art. 165) que estabelece o sistema orçamentário federal regulado por três leis: a Lei do Plano Plurinanual (PPA); a Lei de Diretrizes Orçamentárias (LDO); e a Lei Orçamentária Anual (LOA). O PPA é de periodicidade quadrienal, avançando um ano do próximo governo. O PPA é um instrumento do planejamento municipal que estabelece os objetivos, as estratégias e as ações da administração municipal para as despesas de capital e outras delas decorrentes, bem como para as relativas aos programas de duração continuada. Dele se derivam a LDO e a LOA. A LDO é de periodicidade anual e estabelece um conjunto de instruções em termos de normas de forma e o conteúdo com que a lei orçamentária de cada exercício deve ser apresentada para indicar as prioridades a serem observadas em sua elaboração. A LOA é de periodicidade anual. Proverá os recursos necessários para cada ação constante da LDO. A LOA é uma lei de natureza especial em razão do seu objeto e da forma peculiar de tramitação que lhe é definida.

O plano diretor municipal também pode ser chamado de plano diretor de cidades ou planejamento urbano. Os municípios brasileiros passam e passarão por mudanças profundas que poderão garantir um futuro de desenvolvimento equilibrado. Também poderão universalizar o direito à moradia digna em ambiente saudável para todos os seus munícipes. Para tanto, os municípios têm de contar com fontes estáveis e seguras de financiamento para o desen- 
volvimento urbano indispensáveis para que os municípios possam manter e expandirem-se adequada e democraticamente. Entretanto, para que isso seja possível, os cidadãos também terão que enfrentar um grande desafio nos próximos anos, o de instituir formas de planejamento e controle do território municipal. Juntos, a gestão urbana, a gestão municipal e os munícipes podem utilizar os potenciais e limites do seu meio físico, as potencialidades abertas pela existência de redes de transporte e logística em seus territórios de forma que os impactos de seu crescimento e desenvolvimento não se traduzam em desequilíbrios e deseconomias. Planejar o futuro do município, incorporando todos os setores sociais, econômicos e políticos que o compõem, de forma a construir um compromisso entre cidadãos e governos na direção de um projeto que inclua todos, é o desafio do Estatuto das Cidades (Brasil, 2004).

Os princípios que norteiam o plano diretor municipal estão contidos no Estatuto das Cidades. Nele, o plano diretor está definido como instrumento básico para orientar a política de desenvolvimento e de ordenamento da expansão urbana do município. Até 2006, é obrigatório para municípios com mais de 20 mil habitantes; integrantes de regiões metropolitanas e aglomerações urbanas; com áreas de especial interesse turístico; situados em áreas de influência de empreendimentos ou atividades com significativo impacto ambiental na região ou no país (Brasil, 2005).

Para que o planejamento plurianual e o plano diretor municipais sejam elaborados, devem atender os requisitos da legislação vigente que requer a sua aprovação por lei municipal, definição de zonas urbanas e rurais, participação popular e demais particularidades.

\section{Premissas dos planejamentos municipais}

Antes de o município elaborar os seus planejamentos municipais, algumas premissas e conceitos devem ser entendidos, discutidos e disseminados (Rezende e Castor, 2005). As principais premissas podem ser: informação e conhecimento no município e na prefeitura; administração estratégica e de pensamento estratégico; gestão urbana e gestão municipal; políticas e projetos participativos municipais.

A informação deve ser a primeira premissa a ser considerada, pois sem informação não será possível elaborar e implementar esse projeto. Merecem atenção especial nos planejamentos municipais as informações personalizadas, as informações oportunas das prefeituras e dos municípios. Também merecem destaque os conhecimentos dos munícipes. 
Não só as funções da administração (planejamento, organização, direção e controle) devem ser consideradas num planejamento estratégico municipal, os conceitos e preceitos da administração estratégica e do pensamento estratégico devem ser vivenciados na sua elaboração. Os conceitos de gestão, gestão urbana e gestão municipal também devem ser contextualizados no projeto de planejamento estratégico municipal. Tanto a gestão urbana quanto a gestão municipal podem estar relacionadas com os conceitos de new public management e de inteligência organizacional. As políticas públicas e os projetos participativos também estão intimamente relacionados com os planejamentos municipais.

\section{Conceito e integração dos planejamentos municipais}

Para elaboração dos planejamentos municipais é relevante discutir coletivamente seu significado, adotar um conceito e vivenciar os conceitos adotados.

O planejamento estratégico municipal é um processo dinâmico e interativo para determinação dos objetivos, estratégias e ações do município e da prefeitura. É elaborado por meio de diferentes e complementares técnicas administrativas com o total envolvimento dos atores sociais, ou seja, munícipes, gestores locais e demais interessados na cidade. É formalizado para articular políticas federais, estaduais e municipais visando produzir resultados no município e gerar qualidade de vida adequada aos seus munícipes. É um projeto urbano global que considera os aspectos sociais, econômicos e territoriais. É uma forma participativa e contínua de pensar o município no presente e no futuro. A realização do planejamento estratégico municipal de forma coletiva e participativa oferece para os municípios e seus munícipes apenas benefícios. Não são conhecidos retornos negativos desse projeto. O desenvolvimento local é indiscutível e a melhora da qualidade de vida dos munícipes é incontestável (Rezende e Castor, 2005).

Os municípios preocupados com seu sucesso e com a qualidade de vida dos seus munícipes devem integrar ou alinhar os seus diferentes planejamentos. Os planejamentos nos municípios podem compreender os seguintes instrumentos integrados: planejamento plurianual, plano diretor, planejamento estratégico, políticas, projetos participativos, planejamento de recursos humanos e planejamento de informações e tecnologias (Rezende e Castor, 2005). A figura 1 mostra a integração sugerida. 
Figura 1

Integração dos planejamentos municipais

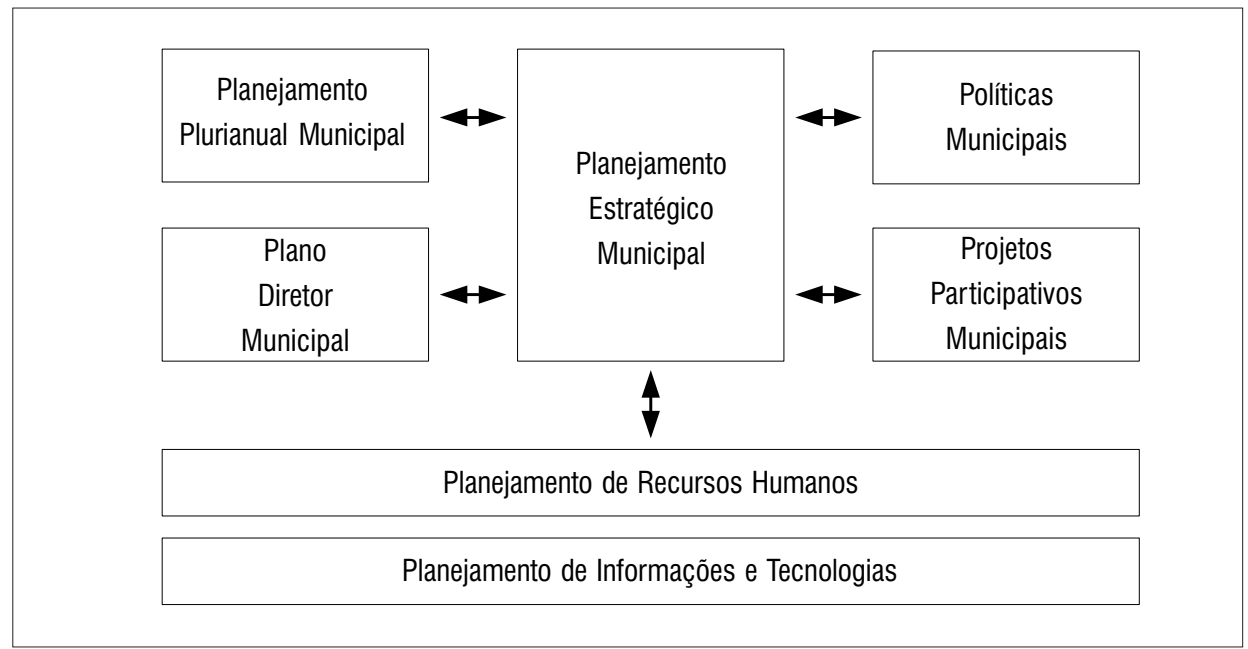

Fonte: Rezende e Castor, 2005.

O planejamento plurianual municipal tem foco orçamentário enquanto o plano diretor municipal tem foco no desenvolvimento e expansão territorial urbana. Todos esses instrumentos de planejamentos nos municípios devem estar integrados ou alinhados para efetivamente alcançar seus objetivos. O planejamento estratégico municipal integra-se com o planejamento plurianual municipal e com o plano diretor municipal pelas trocas de objetivos, estratégias e ações municipais. As políticas e os projetos participativos municipais integram-se com o planejamento estratégico municipal pelas regulações, intervenções, pressões e participações políticas e sociais dos munícipes, gestores locais e demais interessados na cidade. Para a viabilização do planejamento estratégico municipal será necessário planejar os recursos humanos, as informações e as tecnologias. O não-planejamento dessas variáveis tem causado insucesso na elaboração e na implementação do planejamento estratégico municipal.

O planejamento de recursos humanos está relacionado com a discussão, definição e capacitação das pessoas requeridas para a implementação do planejamento estratégico municipal. Num primeiro momento deverá ser definido o perfil profissional necessário para a elaboração do projeto de planejamento estratégico municipal. Esse perfil está direcionado para as habilidades necessárias para o projeto, que contempla o domínio das habilidades técnicas, dos serviços municipais e humana ou comportamental. As habilidades técnicas di- 
zem respeito ao domínio dos instrumentos de planejamento estratégico municipal. As habilidades dos serviços municipais dizem respeito ao entendimento dos serviços prestados pela prefeitura e pelo município. E as habilidades humanas dizem respeito às relações pessoais requeridas em todas as atividades profissionais. Num segundo momento deverá ser definido o perfil das pessoas para a implementação dos objetivos, estratégias e ações municipais constantes no projeto de planejamento estratégico municipal.

O planejamento das informações e das tecnologias está relacionado com a discussão, definição e organização das informações e das tecnologias necessárias para a elaboração e implementação do planejamento estratégico municipal.

\section{Organização e metodologia do planejamento estratégico municipal}

A primeira atividade requerida para elaboração do planejamento estratégico municipal é a sua organização preliminar. Para isso será necessário definir os objetivos do planejamento estratégico municipal e adotar uma metodologia para esse projeto coletivo e participativo. Além dessas duas atividades, também se recomenda entender, estudar, rever, elaborar ou ajustar os demais planejamentos municipais (Rezende e Castor, 2005).

Os objetivos do planejamento estratégico municipal estão relacionados com as múltiplas atividades de definição e esclarecimento coletivo do que se almeja para o município, principalmente por parte dos munícipes, dos gestores locais e dos demais interessados na cidade. Os objetivos devem ser amplamente discutidos e coletivamente assumidos. A formalização dos objetivos prepara as pessoas para a elaboração do planejamento estratégico municipal por meio de roteiro e métodos determinados para sua planificação. Trata-se de um processo que leva ao estabelecimento de um conjunto coordenado de ações municipais coletivas visando determinados alvos predefinidos. Tendo em vista que o planejamento estratégico municipal envolve interesses diferentes e divergentes, estabelecer o objetivo coletivo para esse projeto é fundamental para o seu sucesso e é inexorável para a convivência das pessoas envolvidas.

A equipe multidisciplinar constitui uma parte fundamental para o sucesso desse projeto coletivo e participativo. As partes ou fases e as respectivas subfases da metodologia adotada do planejamento estratégico municipal devem ser elaboradas pelos componentes da equipe multidisciplinar atuando de forma interdisciplinar e coletiva. Em alguns projetos a equipe multidisciplinar também é chamada de equipe multifuncional, de time de trabalho ou célula de atividades. Em especial, no planejamento estratégico municipal, essa equipe 
também pode ser chamada de comitê de trabalho, incluindo inclusive os demais interessados na cidade (atores sociais ou stakeholders).

Os comitês de trabalho podem ser compostos pelos seguintes grupos de pessoas: conselho do município, conselho municipal ou conselho da comunidade local; conselho diretor ou patrocinadores do planejamento estratégico municipal; comitê gestor ou comitê executivo, ou equipe multidisciplinar coordenadora do planejamento estratégico municipal; grupos de trabalho, comissões especializadas ou conselhos setoriais; e assessores externos.

Após nominar a equipe multidisciplinar ou os comitês de trabalho responsáveis pela elaboração e implementação do planejamento estratégico municipal, será necessário capacitar todas as pessoas que constituem esses comitês e, posteriormente, planejar as atividades para cada pessoa dentro desses comitês.

Todo projeto deve ser elaborado com uma metodologia adequada, viável, dinâmica e inteligente. Como o planejamento estratégico municipal é um projeto do município, ele requer uma metodologia coletiva para sua elaboração e implementação. Uma metodologia para o planejamento estratégico municipal pode se constituir em uma abordagem organizada para alcançar o sucesso do projeto por meio de passos preestabelecidos. Uma metodologia é basicamente um roteiro sugerido. Também pode ser entendida como um processo dinâmico e interativo para desenvolvimento estruturado e inteligente de projetos, visando a produtividade e efetividade de projetos. Permite o uso de uma ou várias técnicas por opção dos envolvidos no projeto.

\section{Fases do planejamento estratégico municipal}

Para elaborar e implementar o planejamento estratégico municipal sugere-se uma metodologia com as seguintes fases: análises estratégicas; diretrizes estratégicas; estratégias e ações municipais; e controles municipais e gestão do planejamento (Rezende e Castor, 2005).

As análises estratégicas podem corresponder à primeira fase do processo de planejamento estratégico municipal. É uma questão de opção das equipes envolvidas, embora possa ser elaborada concomitantemente com a fase de diretrizes estratégicas. As análises estão relacionadas com observações críticas, decomposições de atividades, classificações de ações, apreciações detalhadas, monitoramentos específicos, exames minuciosos e possibilidades de correções. As análises estratégicas podem ser divididas em três partes: do município, externas ao município e da administração municipal.

As diretrizes estratégicas podem corresponder à segunda fase do processo de planejamento estratégico municipal. Nada impede que seja elaborada 
concomitantemente com a fase de análises estratégicas. As diretrizes estão relacionadas com traçados de caminhos, com programas de atividades, com conjuntos de instruções, com indicações de ações e com normas ou procedimentos. As diretrizes estratégicas podem ser divididas em duas partes: do município e da administração municipal. As diretrizes do município podem ser divididas nas subfases: visão, vocações e valores ou princípios do município e dos cidadãos; e objetivos municipais. Já no que diz respeito à prefeitura, o projeto pode ser dividido nas seguintes subfases: missão, atividades, políticas e procedimentos organizacionais municipais.

As estratégias e as ações municipais constituem uma importante fase do projeto ou etapa do processo do planejamento estratégico municipal. Na maioria das metodologias de planejamento estratégico municipal, essa fase é elaborada após a realização das duas fases anteriores (análises estratégicas e diretrizes estratégicas). Mas não há nenhum impedimento de que sejam definidas algumas estratégias e as ações municipais no início do planejamento estratégico municipal. Outra possibilidade plausível é que as estratégias e ações municipais possam ser elaboradas de maneira simultânea com as demais fases. As ações podem ser entendidas como os atos ou efeitos de agir, de atuar, de fazer acontecer como uma manifestação de uma força, de uma energia, de um agente, de uma comunidade. As ações municipais oportunizam as diversas possibilidades ou alternativas para realizar as estratégias municipais, levando em conta as suas viabilidades (financeiras e não-financeiras), os recursos, as leis e, acima de tudo, a necessidade da vontade da comunidade local.

Os controles municipais podem se constituir na última fase do projeto ou pode ser utilizado nas fases e subfases do processo do planejamento estratégico municipal. Os principais objetivos dessa fase são a definição de padrões e medição de desempenho, o acompanhamento, a correção de desvios e a garantia do cumprimento do planejamento estratégico municipal. Também visa analisar como está uma determinada atividade do planejamento estratégico municipal, avaliando seu resultado e proporcionando eventuais ações de mudanças. Essencialmente um processo de controle municipal enfatiza o estabelecimento de indicadores para posterior medição, acompanhamento e avaliação. Nesse sentido, é fundamental estabelecer os meios de controles do planejamento estratégico municipal. Os municípios sofrem controles por meio de instrumentos legais onde o planejamento estratégico municipal deve respeitar a Constituição Federal, a Lei de Responsabilidade Fiscal, o Estatuto das Cidades e a Lei Orgânica Municipal. Para realizar essa fase pode-se incluir: auditorias municipais, indicadores, sistemas de informação e os sistemas de conhecimento. 
O planejamento estratégico municipal deve ser visto como um projeto, como um empreendimento. É dessa forma que o Project Management Institute (PMI) enxerga todos os projetos e estabelece os respectivos padrões de gerenciamento no Project management body of knowledge ( $P M B O K)$. Um projeto é um esforço que tem o objetivo de criar um produto ou um serviço único. O gerenciamento de projetos é a aplicação de conhecimentos, habilidades, perfis, técnicas e ferramentas às atividades do projeto, para atingir ou exceder as necessidades e as expectativas dos envolvidos e os interessados no projeto (PMI, 2000).

\section{Metodologia de planejamento de informação, conhecimento e informática nas prefeituras e municípios}

Adequação, dinamismo e inteligência são requisitos inexoráveis para elaborar com sucesso um projeto de planejamento estratégico, tático e operacional dos sistemas de informação e de conhecimento e da informática ou tecnologia da informação nas prefeituras e municípios.

\section{Introdução}

Uma metodologia completa constitui-se de uma abordagem organizada para atingir um objetivo, por meio de passos preestabelecidos. É um roteiro, um processo dinâmico e interativo para desenvolvimento estruturado de projetos, visando a qualidade, produtividade e efetividade de projetos. A metodologia é um roteiro que permite o uso de uma ou várias técnicas por opção dos desenvolvedores de um projeto. A metodologia deve auxiliar o desenvolvimento de projetos, de modo que atendam de maneira adequada as necessidades do gestor local, munícipe, cliente ou usuário, com os recursos disponíveis e dentro de um prazo ideal definido em conjunto com os envolvidos. Não deve limitar a criatividade profissional, mas deve ser um instrumento que determine um planejamento metódico, que harmonize e coordene as áreas envolvidas. O que limita a criatividade não é a metodologia, mas os requisitos de qualidade, produtividade e efetividade de um projeto.

A metodologia deve ser de toda a prefeitura (ou município) e para toda a prefeitura (ou município) de maneira que seja elaborada e utilizada por todos. Ela deve ser amplamente discutida e detalhadamente avaliada por todos os envolvidos (direta e indiretamente) por meio de uma equipe multidisciplinar. Também deve ser revisada, atualizada e complementada na medida do desenvolvimento dos projetos. 


\section{Premissas e justificativas}

São três as premissas necessárias para a elaboração de projetos de forma metodológica: modularidade, existência e equipe multidisciplinar. A modularidade não tolera o desenvolvimento de projetos sem metodologia. A segunda premissa retrata que um projeto sempre deve ser desenvolvido com uma metodologia, mesmo que ainda não esteja fortemente sedimentada. Todo e qualquer projeto deve ser elaborado por meio de metodologia estruturada, moderna, inteligente e que ofereça documentação completa. Toda organização (privada ou pública) deve ter uma metodologia, visando a efetividade, continuidade, perenidade, segurança e transparência, aceita e implementada pelos gestores locais, munícipes, servidores, clientes ou usuários e desenvolvedores de projetos, sistemas, sejam componentes internos da prefeitura ou dos prestadores de serviços.

As justificativas do desenvolvimento de projetos por meio de metodologias devem ser formalizadas de modo a que seus produtos: forneçam a visão do estado do projeto a qualquer instante; sirvam como meio de comunicação entre os envolvidos; indiquem o nível de participação de todos os envolvidos; detalhem nos níveis adequados aos interesses da equipe envolvida; mantenham um histórico documental do projeto; sejam sempre bases para as fases e subfases seguintes.

A metodologia requer seu desmembramento em fases, essas por sua vez em subfases, as quais geram um produto ou mais produtos que devem ser avaliados e aprovados pela equipe multidisciplinar do projeto. Pode-se generalizar o conceito de que "produto" é tudo que é externado no desenvolvimento das subfases de um projeto. As subfases funcionam como guia básico e podem ser ajustadas diferentemente para cada projeto ou organização, considerando, para tal, seus valores organizacionais e culturais, sua realidade e tipo de organização (pública ou privada), bem como, a técnica e a filosofia a ser utilizada.

As avaliações do projeto são os momentos de apresentação e de aprovação para toda a equipe multidisciplinar do projeto, para verificação do grau de satisfação e atendimento às necessidades e aos requisitos do projeto, obedecendo aos padrões de qualidade, produtividade e efetividade estabelecidos. Principalmente o patrocinador e os munícipes devem avaliar a qualidade do projeto. A avaliação, revisão e aprovação devem ser elaboradas em todas as passagens das partes ou fases do projeto, considerando: revisão da(s) partes ou fase(s) imediatamente anterior(es); apresentação dos produtos à gestão da organização (pública ou privada), ao patrocinador, aos gestores, aos munícipes e demais envolvidos; e deferimento formal dos envolvidos. 
A documentação do projeto se constitui na realização do mesmo e nos relatórios, diagramas e descrições formais de cada produto elaborado nas respectivas subfases.

\section{Equipe multidisciplinar}

Como a metodologia é uma ferramenta de trabalho de toda a prefeitura e município, suas fases e subfases devem ser elaboradas por uma equipe multidisciplinar ou multifuncional atuando de forma interdisciplinar. Em alguns projetos também são chamadas de comitês ou times de trabalho ou células de negócios. Essa equipe multidisciplinar reúne talentos de diversas áreas e funções, somando conhecimentos para geração de um produto consistente. Os prestadores de serviços devem se enquadrar na metodologia estabelecida pela contratante, quando for o caso. A equipe deve ser adequada para cada projeto, respeitando sua cultura, filosofia e políticas. Todos os componentes devem possuir seus respectivos planos de trabalho, individuais e coletivos.

O patrocinador ou executivo principal normalmente pode ser um secretário municipal, um diretor ou um gerente da função municipal ou do serviço municipal. Eventualmente também pode ser o prefeito a ocupar esse papel. Também pode ser um representante do cliente da organização contratante. Tem alto poder de decisão, formal e informal, que determina os objetivos específicos e os prazos. Possui forte influência política junto aos outros diretores, gerentes ou gestores públicos. Negocia planejamento e cronogramas. O patrocinador participa das principais reuniões, aprovações e avaliação dos principais resultados e produtos.

O gestor do projeto pode ser um servidor municipal diretamente ligado aos procedimentos operacionais e sistêmicos do projeto. É o "dono" executivo do projeto. Deve ter poder de decisão. Tem participação direta e efetiva no projeto, em todas as reuniões e aprovações e avaliação de todos os resultados e produtos. É responsável pelo cumprimento do planejamento e cronograma. Recomenda-se que o gestor do projeto sempre seja um gestor da prefeitura, principalmente que detenha conhecimento adequado dos serviços municipais oferecidos pela prefeitura.

A equipe da tecnologia da informação é composta por técnicos em informática, tais como analistas de sistemas, engenheiros de software e analistas de suporte, que representam a unidade departamental da tecnologia da informação da prefeitura. Também são os executores das atividades operacionais planejadas, principalmente as que envolvem os recursos tecnológicos. 
A equipe de servidores municipais é composta por servidores municipais, técnicos, engenheiros, assistentes e auxiliares. Deve contemplar pelo menos um representante de cada função municipal ou das secretarias municipais. São os executores das atividades operacionais planejadas para elaboração do projeto. Pode existir no projeto mais de uma equipe de servidores municipais, principalmente quando serão atribuídas atividades especiais ou predefinidas por um tempo limitado.

A equipe de munícipes é composta por munícipes sem vínculo com a prefeitura. Deve contemplar representantes dos interesses locais. Também são chamados de atores sociais ou stakeholders. Atuam principalmente no levantamento de dados e na elaboração dos "modelos de informação" para a formalização das informações necessárias para o acompanhamento da gestão do município e da prefeitura.

Ainda podem aparecer outros componentes para grandes projetos, tais como, gestor técnico, assessores e outros especialistas. O gestor técnico normalmente está diretamente ligado aos procedimentos técnicos da tecnologia da informação do projeto em questão e pode ser o responsável pelo apoio em tecnologia da informação à equipe. Os assessores (ou consultores) podem dar suporte a uma determinada atividade necessária no projeto. O especialista pode ser um engenheiro do conhecimento com domínio, em particular, em um serviço ou negócio determinado ou também em uma ferramenta específica dos recursos da tecnologia da informação.

Toda essa equipe pode ser modificada ao longo do andamento do projeto para ajustar ou redirecionar os seus objetivos e resultados.

\section{Estrutura do projeto de planejamento de informação, conhecimento e informática}

O projeto em prefeituras e municípios deve conter uma estrutura flexível, mas alguns componentes mínimos podem ser sugeridos. Nesse caso, cada item deve ser descrito, deixando claro seus objetivos para facilitar a compreensão dos produtos que devem ser gerados. O projeto pode ser dividido em três grandes partes: capa do projeto, apresentação do projeto e do município e desenvolvimento do projeto.

A capa do projeto deve apresentar pelo menos o nome do município, o nome do projeto e a data da realização. Nas primeiras páginas do projeto recomenda-se elaborar uma apresentação do município com alguns dados locais relevantes. Como opção, um histórico do município, o nome do prefeito, secretários, corpo diretivo e outros papéis relevantes. Também pode ser oportuno 
descrever um contexto atual da tecnologia da informação na prefeitura e um cenário desejado. O desenvolvimento do projeto apresenta e descreve todas as suas partes, fases e subfases, onde são gerados e aprovados os seus respectivos produtos. As aprovações devem ser coletivas e formalmente elaboradas em cada uma das partes e na conclusão do projeto.

\section{Partes e fases do projeto de planejamento de informação, conhecimento e informática}

As fases podem ser apresentadas de forma seqüencial e didática nas chamadas "partes". As fases de cada parte podem ser elaboradas concomitantemente e de forma integrada e complementar uma da outra. A metodologia proposta é composta de nove partes, com suas respectivas fases e subfases (figura 2).

Parte 1. Planejar o projeto contempla as fases: a. Organizar o projeto; b. Capacitar a equipe.

Parte 2. Revisar o planejamento estratégico municipal (PEM) contempla a fase: c. Identificar estratégias e ações municipais. Dentro dessa parte também podem ser revisados os demais planejamentos municipais (planejamento plurianual e plano diretor).

Parte 3. Planejar informações e conhecimentos contempla a fase: d. Identificar informações e conhecimentos municipais.

Parte 4. Avaliar e planejar sistemas de informação e de conhecimentos contempla as fases: e. Avaliar sistemas de informação e de conhecimentos; f. Planejar sistemas de informação e de conhecimentos.

Parte 5. Avaliar e planejar tecnologia da informação contempla as fases: g. Avaliar tecnologia da informação; h. Planejar tecnologia da informação software; i. Planejar tecnologia da informação — hardware; j. Planejar tecnologia da informação — sistemas de telecomunicações; k. Planejar tecnologia da informação - gestão de dados e informação; l. Avaliar infra-estrutura paralela; m. Planejar infra-estrutura paralela; n. Organizar unidade da tecnologia da informação.

Parte 6. Avaliar e planejar recursos humanos contempla as fases: o. Avaliar recursos humanos; p. Planejar recursos humanos.

Parte 7. Priorizar e custear o projeto contempla as fases: q. Estabelecer prioridades e necessidades; r. Avaliar impactos; s. Elaborar plano econômicofinanceiro.

Parte 8. Executar o projeto contempla a fase: t. Elaborar planos de ação.

Parte 9. Gerir o projeto contempla a fase: u. Gerir, divulgar, documentar e aprovar. 
Os softwares de governo eletrônico, os portais públicos municipais e outros projetos ou produtos municipais específicos, são analisados e planejados nessas três partes: 3. Planejar informações e conhecimentos; 4. Avaliar e planejar sistemas de informação e de conhecimentos; e 5. Avaliar e planejar tecnologia da informação. Na parte 3 as informações necessárias são modeladas. Na parte 4 todos os sistemas de informações e de conhecimentos relacionados com esses projetos são detalhadamente analisados e posteriormente planejados. Na parte 5 serão analisadas e planejadas as tecnologias e respectivas infra-estruturas necessárias para viabilizar esses projetos municipais.

Figura 2

Visão geral da metodologia do projeto de planejamento de informação, conhecimento e informática

\begin{tabular}{|c|c|c|c|c|}
\hline \multirow[t]{2}{*}{$\begin{array}{c}\text { 1. Planejar } \\
\text { projeto }\end{array}$} & $\begin{array}{l}\text { 2. Revisar } \\
\text { planejamento } \\
\text { estratégico } \\
\text { municipal }\end{array}$ & $\begin{array}{l}\text { 4. Avaliar e } \\
\text { planejar } \\
\text { sistemas }\end{array}$ & $\begin{array}{l}\text { 5. Avaliar e } \\
\text { planejar } \\
\text { tecnologia da } \\
\text { informação }\end{array}$ & $\begin{array}{l}\text { 7. Priorizar e } \\
\text { custear } \\
\text { projeto }\end{array}$ \\
\hline & $\begin{array}{l}\text { 3. Planejar } \\
\text { informações e } \\
\text { conhecimentos }\end{array}$ & & $\begin{array}{l}\text { 6. Avaliar e } \\
\text { planejar } \\
\text { recursos } \\
\text { humanos }\end{array}$ & $\begin{array}{l}\text { 8. Executar } \\
\text { projeto }\end{array}$ \\
\hline \multicolumn{5}{|c|}{ 9. Gerir projeto } \\
\hline
\end{tabular}

Algumas prefeituras e municípios preferem elaborar o projeto estruturado pelas partes sugeridas. Outras elaboram o projeto com as subfases agrupadas por finalidade, tais como: organizar o projeto, identificar e avaliar determinados itens, propor ou planejar determinados itens, executar o planejamento, e outras. É possível também, elaborar os produtos como versões e "lapidá-los" nas discussões e aprovações das equipes multidisciplinares ou comitês envolvidos.

As fases ou etapas, subfases e tarefas podem ser adequadas, complementadas ou suprimidas de projeto para projeto. O nível de detalhamento de cada subfase deve ser determinado pela equipe multidisciplinar do projeto, de acordo com o grau de necessidade da prefeitura e município e do momento em que se encontram.

Para a elaboração de algumas fases recomenda-se a criação de formulários para documentar as respectivas atividades. Esses formulários podem conter: 
nome do município, nome do documento, responsável(eis) pelo preenchimento, data da elaboração ou referência, e respectivos campos a serem preenchidos.

Ao final de cada subfase recomenda-se a elaboração de quadros resumos (sintéticos ou gerais) que têm como objetivo a apresentação para o patrocinador e outros gestores locais, que freqüentemente não dispõem de muito tempo para o acompanhamento e as aprovações do projeto.

\section{Subfases do projeto de planejamento de informação, conhecimento e informática}

Cada uma das fases pode ser composta por uma ou mais subfases.

Fase a. Organizar o projeto contempla as subfases: nominar a equipe multidisciplinar do projeto (ou comitê); definir objetivos do projeto; definir metodologia do projeto.

Fase b. Capacitar a equipe de trabalho: capacitar equipe no projeto; planejar atividades do projeto.

Uma única subfase para a fase c. Identificar objetivos, estratégias e ações municipais.

Fase d. Identificar informações e conhecimentos municipais contempla as subfases: modelar informações municipais; mapear conhecimento.

Fase e. Avaliar sistemas de informação e de conhecimentos: elaborar plano de trabalho; identificar sistemas da prefeitura e cidade; descrever sistemas da prefeitura e cidade; avaliar e sumariar a situação dos sistemas da prefeitura e da cidade.

Fase f. Planejar sistemas de informação e de conhecimento: rever e detalhar informações e conhecimentos; nominar sistemas propostos; diagramar sistemas propostos; descrever sistemas propostos; validar sistemas propostos; avaliar aquisição ou desenvolvimento dos sistemas propostos; elaborar quadro demonstrativo dos sistemas propostos.

Fase g. Avaliar tecnologia de informação: elaborar plano de trabalho; identificar tecnologia da informação; descrever e avaliar software; descrever e avaliar hardware; descrever e avaliar sistemas de telecomunicação; descrever e avaliar gestão de dados e informação; descrever e avaliar políticas de tecnologia da informação; elaborar quadro demonstrativo da tecnologia da informação.

Fases h. Planejar software, i. Planejar hardware, j. Planejar sistemas de telecomunicações, k. Planejar gestão de dados e informação contemplam respectivamente as subfases: desenvolver estratégias específicas; definir políticas; definir normas e padrões técnicos operacionais; configurar tecnologia da informação; elaborar quadro demonstrativo. 
Fase 1. Avaliar infra-estrutura paralela: elaborar plano de trabalho; identificar infra-estrutura paralela; descrever e avaliar infra-estrutura paralela; descrever e avaliar políticas; elaborar quadro demonstrativo.

A fase $\mathbf{m}$. Planejar infra-estrutura paralela: desenvolver estratégias de infraestrutura paralela; definir políticas; definir normas e padrões técnicos operacionais; configurar infra-estrutura paralela; elaborar quadro demonstrativo.

A fase $\mathbf{n}$. Organizar a unidade da tecnologia da informação: elaborar plano de trabalho; avaliar unidade; definir e propor estratégias; definir modelo de gestão; definir políticas; definir normas e padrões técnicos operacionais; propor estrutura organizacional; elaborar quadro demonstrativo.

Fase o. Avaliar recursos humanos: elaborar plano de trabalho; identificar e descrever funções ou cargos; identificar e descrever perfil profissional; avaliar competências e habilidades; rever estrutura organizacional; avaliar processos de recrutamento e seleção; avaliar processos de capacitação e de competências; elaborar quadro demonstrativo.

Fase p. Planejar recursos humanos: propor estratégias; propor estrutura organizacional; definir perfil profissional; planejar necessidades de capacitação; propor processos de recrutamento e seleção, processos de capacitação e competências, políticas de gestão de pessoas; elaborar quadro geral dos recursos humanos necessários.

Fase q. Estabelecer prioridades e necessidades: definir critérios de prioridades; elaborar quadro prioridades; relatar recursos necessários.

Fase r. Avaliar impactos: identificar impactos do projeto na prefeitura e na cidade; descrever impactos e alternativas; elaborar quadro demonstrativo dos impactos e recomendações.

Fase s. Elaborar plano econômico-financeiro: desenvolver estratégias e políticas de retorno dos investimentos; elaborar análise de custos, benefícios, riscos e viabilidade; elaborar quadro demonstrativo.

Fase t. Elaborar planos de ação: elaborar planos de trabalho para as soluções propostas; e quadro demonstrativo dos planos de ação.

Fase u. Gerir, divulgar, documentar e aprovar o projeto que está presente em todas as outras fases é dividida nas subfases: definir forma de gestão; gerir projeto; divulgar projeto; documentar projeto; apresentar, avaliar e aprovar projeto.

\section{Relação da metodologia proposta com gerenciamento de projetos}

O gerenciamento de projetos é um fator de sucesso para as organizações que elaboram projetos ou desenvolvem soluções, principalmente porque o número 
de projetos que não chegam ao seu final com sucesso é muito alto. Nas prefeituras e municípios não é diferente. Isso ocorre principalmente pela falta de acompanhamento do cliente do projeto (principalmente o patrocinador, o gestor e os munícipes), pela falta de comprometimento da equipe do projeto, resistência ao planejamento, deficiência dos requisitos funcionais do projeto e pela incompetência dos envolvidos.

O projeto de planejamento de sistemas de informação e de conhecimento e da informática ou tecnologia da informação nas prefeituras e municípios deve ser visto como um empreendimento ou como parte de um empreendimento da prefeitura e município. É dessa forma que o PMI enxerga projetos e estabelece padrões de gerenciamento de projetos no $P M B O K$.

Um projeto é um esforço temporário (empreendimento) que tem o objetivo de criar um produto ou um serviço único. O gerenciamento de projetos é a aplicação de conhecimentos, habilidades, perfis, técnicas e ferramentas às atividades do projeto, para atingir ou exceder as necessidades e as expectativas dos envolvidos e os interessados no projeto (PMI, 2000). Os projetos podem ser considerados como um conjunto de processos, estabelecidos em duas categorias de macroprocessos: processos orientados ao gerenciamento de projetos (iniciar, planejar, executar, controlar e encerrar) e processos orientados aos produtos do projeto.

No caso do projeto de planejamento de sistemas de informação e de conhecimento e de informática ou tecnologia da informação nas prefeituras e municípios, uma metodologia para a sua elaboração é fundamental. Essa metodologia pode ser complementada pelas áreas do conhecimento do gerenciamento de projetos.

O gerenciamento de projetos é organizado em áreas de conhecimento, onde cada uma é descrita por meio de processos. Essencialmente cada área de conhecimento se refere a um aspecto a ser considerado dentro da gestão de projetos. São recomendadas nove áreas de conhecimento em gerenciamento de projeto para a obtenção de sucesso nessa atividade: integração, escopo, tempo, custos, qualidade, recursos humanos, comunicações, riscos e suprimentos e contratos (PMI, 2000). Todas essas áreas estão respectivamente relacionadas com a metodologia de projeto proposta e estão integradas aos seus cinco grupos ou fases: iniciação ou definição, planejamento, execução, controle e encerramento ou finalização.

\section{Conclusão}

A proposta sugerida de uma metodologia diferenciada para o projeto de planejamento de informação, conhecimento e informática nas prefeituras e muni- 
cípios pode constituir um instrumento de gestão das prefeituras e dos municípios de relevância inquestionável. Principalmente quando for elaborado juntamente com o projeto de planejamento estratégico municipal com seus preceitos do empreendedorismo e com a efetiva participação dos munícipes. Ambos os projetos são atuais, inexoráveis e necessários nos municípios. Essa proposta pode contribuir com os municípios que estão preocupados com os desafios sociais, políticos, financeiros e de gestão.

Para atender os objetivos deste artigo, foram descritas fases, subfases e produtos de uma metodologia para projeto de planejamento de informação, conhecimento e informática nas prefeituras e municípios integrados ao planejamento estratégico municipal. Também foi detalhada de forma objetiva a visão moderna e a aplicação adequada de um guia para planejamento das informações dos municípios e das prefeituras.

Foram contextualizados os demais planejamentos do município, ou seja, o planejamento plurianual, o plano diretor, os projetos participativos municipais e o planejamento de recursos humanos. Tais planejamentos são integrados por meio das políticas municipais estabelecidas e das legislações específicas.

O projeto de planejamento proposto juntamente com os demais planejamentos municipais integrados pode facilitar as atividades operacionais, gerenciais e estratégicas das prefeituras e municípios. Tal facilitação também está pautada na obediência à Lei de Responsabilidade Fiscal, na exigência do Estatuto das Cidades e nas pressões dos munícipes e dos interessados na cidade (atores sociais ou stakeholders).

Nesse sentido, as atividades de planejamento municipais e de implementação dos objetivos, das estratégias e das ações municipais são compartilhadas com os munícipes e com os interessados na cidade. Por um lado esse compartilhamento pode ajudar ou tornar menos densa a administração local e as atividades dos prefeitos e secretários, pois as atuações desses gestores locais seriam descentralizadas e provavelmente mais ágeis e efetivas. Isso corroboraria com o compartilhamento do poder do governo municipal com os munícipes e demais interessados na cidade. Por outro lado, a efetiva participação dos munícipes no planejamento estratégico municipal motiva os cidadãos a entender e vivenciar o município. Também valoriza a sua vida cívica, permite o envolvimento no crescimento de seu município e possibilita o desenvolvimento de ações sociais e políticas de seu município. Isso pode diminuir suas angústias e suas pressões sem propósito junto à administração local. Ambas as abordagens podem cooperar nos fatores competitivos entre os municípios e no conseqüente aumento da qualidade de vida dos seus munícipes.

Para que o projeto de planejamento de informação, conhecimento e informática nas prefeituras e municípios alcance seus objetivos, deve estar 
integrado aos planejamentos municipais. Preferencialmente devem ser elaborados de forma participativa com os munícipes. Quando o município possui um planejamento estratégico municipal documentado, a parte 2 (Revisar o planejamento estratégico municipal) do projeto de planejamento de informação, conhecimento e informática já estará concluída, bastando apenas a sua revisão e aprovação. Em outras palavras, o projeto será mais confiável e adequado se o planejamento estratégico municipal estiver formalmente elaborado.

As informações modeladas no projeto, bem como os conhecimentos mapeados, serão a base para configuração de toda a tecnologia da informação necessária para atender as exigências sistêmicas da prefeitura e município. E para atender as necessidades sistêmicas (sistemas de informação e de conhecimentos) serão definidos os perfis profissionais das pessoas requeridas (servidores e até mesmo os munícipes). Os modelos de informações, os mapas de conhecimentos, as configurações da tecnologia da informação e os perfis profissionais devem atender plenamente os objetivos e as estratégias do município.

Para que os projetos de planejamento estratégico municipal e de planejamento de informação, conhecimento e informática nas prefeituras e municípios obtenham seu sucesso, foram apresentadas algumas premissas que devem ser amplamente discutidas, entendidas e disseminadas. Destacaram-se as premissas: informação e conhecimento no município e na prefeitura; administração e pensamento estratégicos; empreendedorismo; gestões urbana e municipal; projetos participativos municipais; e políticas municipais. Em especial, os conceitos e preceitos do empreendedorismo devem receber atenção diferenciada pelos munícipes, pelos demais interessados na cidade e principalmente pelos gestores locais. Essas pessoas devem adquirir as habilidades requeridas pelo perfil empreendedor e incorporar o espírito empreendedor para se envolver nos problemas dos municípios e nas respectivas propostas de soluções participativas. Tais premissas permitem que o planejamento e a gestão municipal não dependam exclusivamente de um plano de governo limitado ao mandato, pois os objetivos e as estratégias municipais extrapolam esse tempo predefinido e permitem gerar cenários para muitos anos futuros.

Também é fundamental estabelecer um esforço no município para entender os pormenores dos planejamentos municipais e suas integrações. Os municípios atentos ao seu sucesso e à qualidade de vida dos seus munícipes devem integrar ou alinhar os seus diferentes planejamentos, principalmente o planejamento plurianual, o plano diretor, o planejamento estratégico municipais e o planejamento de recursos humanos.

Antes da elaboração do projeto de planejamento de informação, conhecimento e informática nas prefeituras e municípios é fundamental estabelecer a sua organização e a sua metodologia. Essas duas atividades devem ser discu- 
tidas, entendidas e minuciosamente trabalhadas de forma coletiva para evitar problemas, desgastes pessoais e perda de tempo. A metodologia sugerida foi composta por partes, fases e subfases retroalimentadas.

Quanto às contribuições deste artigo, a metodologia proposta pode propiciar uma maneira empreendedora de planejar as informações necessárias e conduzir os municípios e as prefeituras no que diz respeito às práticas cotidianas de gestão municipal visando minimizar os problemas relacionados com as implicações de planejamentos aqui discutidos e apresentados. Para a academia, essa pesquisa pode contribuir nos estudos teóricos e em pesquisas aplicadas em municípios e em prefeituras para entender e sugerir alternativas para os seus desafios emergentes de planejamento e de gestão que envolve seus munícipes, servidores, gestores locais, demais interessados na cidade e os municípios circunvizinhos.

A principal limitação deste artigo está relacionada com o estudo empírico embasado nas experiências vivenciadas do autor pesquisador em projetos de assessoramento em prefeituras e em projetos acadêmicos elaborados pelo grupo de pesquisa num programa de mestrado. Isso nem sempre reflete a realidade aprofundada de todos os municípios. Outras pesquisas e estudos podem ser elaborados a partir deste, principalmente os direcionados a melhorar a metodologia proposta, sejam nos métodos científicos ou como respostas para novas questões.

Finalizando, observa-se que apesar da metodologia proposta ser adequada e viável, o que de fato viabiliza o projeto de planejamento de informação, conhecimento e informática nas prefeituras e municípios são os fatores humanos. Principalmente os relacionados com a vontade dos munícipes em participar do município, os valores positivos dos cidadãos e a competência profissional dos servidores municipais, expressos no inter-relacionamento entre essas pessoas. Esses fatores integrados podem diminuir a exclusão social no município e aumentar participação política dos munícipes visando a sua adequada qualidade de vida.

\section{Referências bibliográficas}

BRASIL. Ministério das Cidades. Plano diretor participativo: guia para elaboração pelos municípios e cidadãos. Brasília: Confea, 2004.

. Ministério das Cidades. Programas urbanos. Disponível em: < www.municípios.gov.br> . Acesso em: 22 fev. 2005.

DAVENPORT, T. H.; PRUSAK, L. Ecologia da informação. São Paulo: Futura, 1998. 
GIL, A. C. Métodos e técnicas de pesquisa social. 5. ed. São Paulo: Atlas, 1999.

KROENKE, D. Management information systems. São Paulo: McGraw-Hill, 1992.

LAUDON, K. C.; LAUDON, J. P. Management information systems: a contemporary perspective. New York: MacMillan, 1996.

MARCONI, M. A.; LAKATOS, E. M. Técnicas de pesquisa. 3. ed. São Paulo: Atlas, 1996.

NACHMIAS, D.; NACHMIAS, C. Research methods in the social sciences. 3. ed. New York: St. Martin's Press, 1987.

NONAKA, I.; TAKEUCHI, H. Criação do conhecimento na empresa: como as empresas japonesas geram a dinâmica da inovação. Rio de Janeiro: Campus, 1997.

NORTON, P. Introdução à informática. São Paulo: Makron Books, 1996.

O'BRIEN, J. A. Sistemas de informação e as decisões gerenciais na era da internet. São Paulo: Saraiva, 2001.

PMI (PROJECT MANAGEMENT INSTITUTE). PMBOK 2000. A guide to the project management body of knowledge. PMI Standard, CD-ROM.

REZENDE, D. A. Engenharia de software e sistemas de informação. Rio de Janeiro: Brasport, 1999.

. Tecnologia da informação integrada à inteligência empresarial: alinhamento estratégico e análise da prática nas organizações. São Paulo: Atlas, 2002.

. Planejamento de sistemas de informação e informática: guia prático para planejar a tecnologia da informação integrada ao planejamento estratégico das organizações. São Paulo: Atlas, 2003.

Planejamento de informações públicas municipais: guia para planejar sistemas de informação, informática e governo eletrônico nas prefeituras e municípios. São Paulo: Atlas, 2005a.

. Sistemas de informações organizacionais: guia prático para projetos em cursos de administração, contabilidade e informática. São Paulo: Atlas, 2005b.

; ABREU, A. F. Tecnologia da informação aplicada a sistemas de informação organizacionais: o papel estratégico da informação e dos sistemas de informação nas organizações. 3. ed. São Paulo: Atlas, 2003.

; CASTOR, B. V. J. Planejamento estratégico municipal: empreendedorismo participativo nos municípios e prefeituras. Rio de Janeiro: Brasport, 2005.

SANTOS, A. R. et al. (Orgs.). Gestão do conhecimento: uma experiência para o sucesso empresarial. Curitiba: Champagnat, 2001. 
STAIR, R. M. Principles of information systems: a managerial approach. 2. ed. New York: Thomson, 1996.

SVEIBY, K. E. A nova riqueza das organizações: gerenciando e avaliando patrimônios de conhecimento. Rio de Janeiro: Campus, 1998. 